\title{
Monitoring of underground subsurface structures in Ekaterinburg
}

\author{
Anna B. Galieva ${ }^{1, *}$, Vladimir N. Alekhin ${ }^{1}$, and Liliya G. Pastukhova ${ }^{1}$ \\ ${ }^{1}$ Ural Federal University, Institute of Civil Engineering, Ekaterinburg, Russia
}

\begin{abstract}
This paper presents the issues of technical state of subsurface structures in operation and the erection of buildings under available development. It is stated that detailed monitoring of technical state of underground tunnels is essential, since the structure is unique and technologically complex. The aspects of geotechnical monitoring of underground tunnels are considered. The principles of geodesic monitoring of underground rings, tension increase in tube lining and pressure from the building under construction on the ground are described. Recommendations for underground tunnel monitoring are presented.
\end{abstract}

\section{Introduction}

The problem of safety is one of the urgent problems in the building sector. At present, infill development is actively underway including the development near existing subsurface structures in operation. Meanwhile, subsurface structures such as underground tunnels are unique, technically complex and strategically essential for a megapolis as safety of the public depends on the reliability of subsurface structures. This calls for the monitoring of their technical state in order to take timely measures to prevent from negative consequences deteriorating this state $[1,2]$. The experts from UrFU began their work in autumn 2014 to inspect and monitor underground tube lining in line sections between two stations under the building being constructed above the ground. The functional purpose of the object under construction is a multistoried block of flats with nonresidential premises.

\section{The description of the object under construction and the specific features of the site}

The building under construction has a trefoil form in plan consisting of three sections. The load-bearing framework of the building is designed from in-situ reinforced concrete. The joining of walls, pillars, columns with floor structures is considered to be rigid. The construction arrangement of each temperature block of the dwelling provides the stability of its geometric shape, the overall stability and taking up both lateral and vertical loads.

From hydrogeological perspective, the territory under consideration is located in the East-Ural hydrogeological area of crustal water basins. The considerable groundwater level

\footnotetext{
* Corresponding author: a.b.galieva@gmail.com
} 
lowering in the given site at the present stage is recorded on basis of the analysis of hydrogeological situation in the region. The change in the groundwater level position is influenced by the location of the site in and around the depressed effect zone of the existing underground route. The water drawdown work is stopped, the level is gradually recovered. Referring to the results of the research one can see that the level of ground waters on the investigated site gradually grows and eventually reaches the position of natural water table formed during the track of many years.

\section{The research of the object and the identification of geometry parameters}

The inspection of the object is executed before the excavation for a structure stripping. The lining structures of both right and left main line tunnels are rings from ribbed, cast-iron tubes. The soil mass, where the main lime tunnels are located, is composed of filled soil, drift and eluvial sandy clays. According to the customer requirement specification, one should examine the sections of two main line tunnels entering the area of the construction influence and define geometrics of the object. Then, these data were compared with design variables. One should define the ellipticity of each ring in tunnel lining on four diameters: horizontal, vertical and two other diameters at an angle of 450 (Fig. 1). Structural deformation of lining should not affect clearness gauge [3-7].

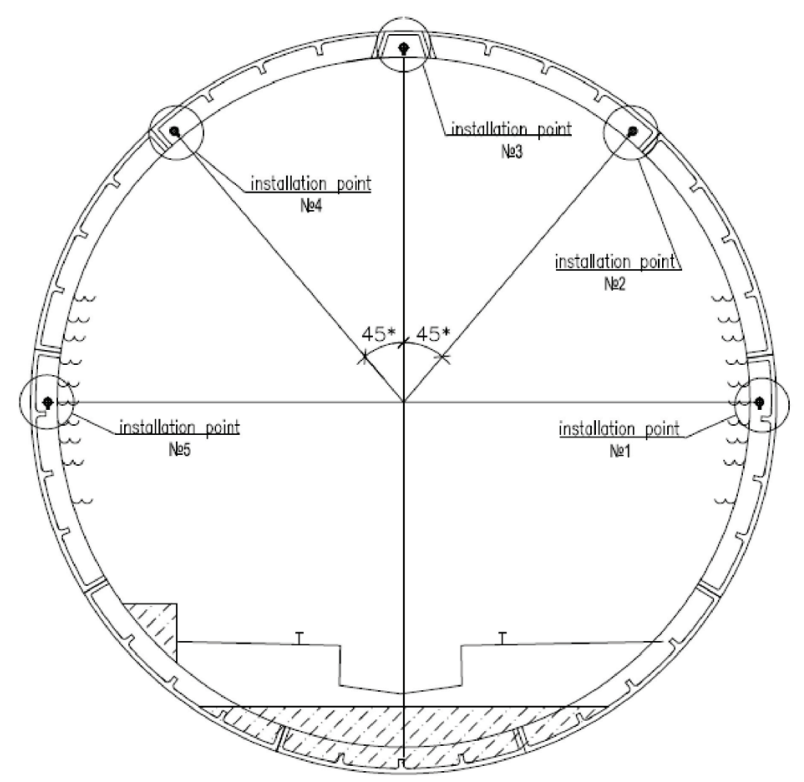

Fig. 1. Installation diagram of deformation control benchmarks to define the ellipticity of tunnellining

When performing visual inspection of tunnels it became evident that tacheometric survey based on five lining points does not provide a complete picture of the strain state of tunnel rings. One may observe local defects on tubing stiffeners that will generally lead to the misperception of clearness gauge (Fig. 2) when entering them. In addition, some essential points of tubing linings are inaccessible for observation because of cables, cantilever brackets and other maintenance-engineering members of tunnel operation system laid along tunnels. 


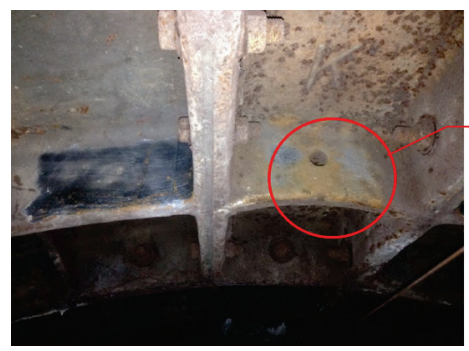

The example of the

local reduction of

the tubing stiffener

cross-section

Fig. 2. The example of local reduction in the cross-section area of an underground tubing stiffener.

The experts from UrFU decided to scan the object using new-generation threedimensional laser tacheometer Leica MS50.

Taking into account the object secrecy, supervised and time limited access, the scanning mesh was chosen so that it was optimal in terms of obtaining fully detailed high quality and time-effective picture. The tunnel scanning from all five basic observation points of the tacheometer was carried out for 25 minutes, and the scanning from all four auxiliary intermediate observation points was carried out for 12 minutes.

Figure 3 gives the example of the image of a separate tunnel ring according to the results of the work.

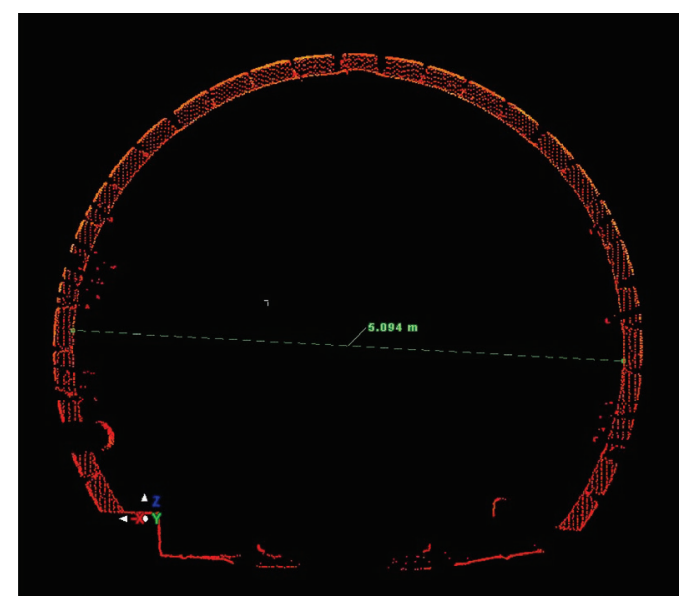

Fig. 3. The example of the scanned lining ring in the underground tunnel.

The inspection of tunnels by means of laser scanning technique allowed investigating the deformation behaviour of the object in detail and detecting weaknesses [8-12]. The quality of the images received enables to scan the members of the tunnel structure including bolts, plug fittings, and structural reinforcement members (Fig. 4). The licensed software packages Leica Cyclone and Leica Infinity were used to process data.

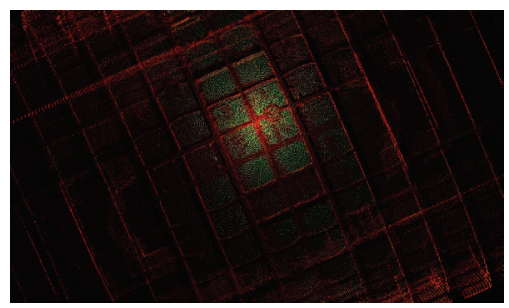

Fig. 4. Overall view of the tunnel structure in the software Leica Infinity. 


\section{Geotechnical monitoring of underground tunnels}

The next stage of the work was to perform geotechnical monitoring of the object including geodesic monitoring (tacheometric survey with the tachometer Leica TM30), tensometry (monitoring system of tension increase in tunnel lining) and registration system of the pressure from the building under construction on the ground. For geodesic monitoring of the tubing stiffeners, five prism deflectors were installed on each ring under test.

At least once a month the inspection is conducted to control the strain state of the structures. The geodesic measurement processing is performed by means of the licensed software packages Leica Geomos Monitor and Leica Geomos Analyzer [13, 15, 16]. To realize the tensometric monitoring, strain gauges were installed on the tubing stiffeners to observe the tension changing in the cast-iron lining of the tubing during the building construction above the tunnels under test [14]. Stringed strain gauges are high-precision gauges and their measured quantity is relative deformation. The strain gauge is a hollow tube with a strain stretched inside. One of the tube ends is stationary; the other is able to move lengthway causing tension or relaxation of a string [17].

Underformed strain gauges were installed into the strain gauges already deformed under the tunnel external load. So, the task of defining the "initial" deformation prior to the building erection as well as tensions acting in lining is technically impractical. Thereby, the technique to record the changes of the relative deformation of the tunnel lining in the points of the gauge installation during the building erection and the tension increase calculation was employed. Tunnel tubes operate under complex multiaxis stress state. When calculating tunnel lining by means of the classical approach, the tubing is assumed to operate mainly under compression with bending, the tunnel cross-sections operate under plain deformation. There is tension system in the tubing net section: radial, tangential and tangent. Tangential tension obtains greater values (in absolute term). Gauges installed on the tunnel lining are oriented in tangential direction (the axis of gauges is pointed tangentially to the lining contour). Strain gauges are installed on the points nearby the edges of longitudinal ribs since the distribution of tangential tensions in tunnel lining thickness is nonuniform, and greater tension values are obtained on the internal and external surfaces of the lining. Thus, the strain gauges are installed in pairs on three points, corresponding to the maxima of bending moments - the point of the largest tangential tensions.

In spring 2015, pressure gauges were installed under the base slab of a dwelling under construction in the areas with maximum tension in order to register the pressure of the building erected on the ground. The gauge consists of two stainless round perimeter-welded plates. The hollow between the plates is filled with deaerated liquid and connected with the sensor by means of stainless steel tube. Any change in pressure on the plate surface results in the change in the hydraulic fluid between the plates, which, in its turn, influences the sensor and causes either the tension or the compression of a string inside the sensor. To record the changes in the string tension, the vibration frequency proper, which is the tension function, is measured. Thus, the changes of pressure on the sensor plates are converted into electric signal that is sent towards the registration point via the cable. The signal cable of each gauge in the corrugated cable is led outside the slab and marked for the further identification when taking the readings.

When the gauge depth level is lower than that of ground waters, pressure gauges should be accompanied with threshold pressure gauges to make provisions for the separation of effective ground pressure from hydrostatic one [18 - 23]. Figure 5 shows the overall view of the construction site and the gauge installation position together with laid signal cables. 


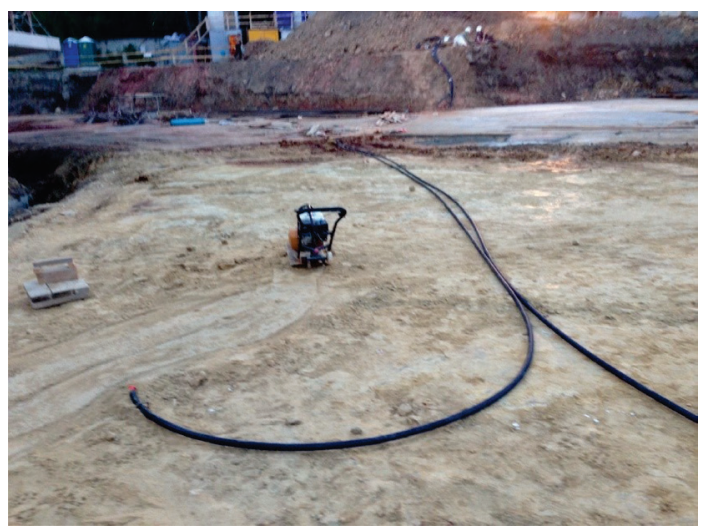

Fig. 5. Overall view of the installation site of pressure gauges.

The strain and pressure gauge readout is performed by means of a portable reader (datalogger) able to transmit the readings via Bluetooth to any android device. The Department of CAD in Civil Engineering, UrFU designed the application for androidplatform-based devices capable of processing gauge readings. The mobile application allows to add photos, drawings, object layouts, to process the readings of a portable datalogger or to enter data in the program manually as well as to construct a table or a graph and to send them to draw an annual report. The overall view of the application work window is shown in Figure 6.

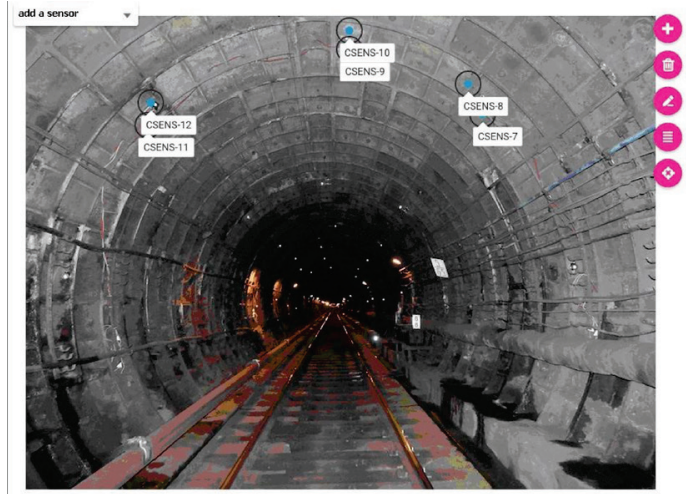

Fig. 6. Overall view of the application work window. The arrangement of strain gauges.

\section{Conclusion}

Monitoring of the object is currently under way; statistical information on the underground tube behaviour is gathered. The behavioural analysis of the subsurface structure performed on schedule allows to size up the impact of new construction on the structure and to develop solutions preventing negative process development.

Measured changes to the shape of the lining are to inform about the overloading of the structure or the fall of the subsoil under the objects above the underground structure. Modern laser measurement currently replaces old methods of monitoring using strain gauges used in the past due to the speed of its implementation over the original methods. 
Implementation of computer-based structure monitoring systems, determination of real structure geometrics by means of three-dimensional laser scanning are recommended when monitoring the existing underground tunnels.

After commissioning the object or stabilizing the design parameter changing, monitoring is permitted quarterly. In the absence of stabilizing of design parameter measuring, geotechnical monitoring should be continued. By the absence of stabilizing of design parameter changing, we consider the excess of parameter values by more than a half of precision of measurement compared with previous cycles.

\section{References}

1. Y. Y. Su, Hashash Y. M. A., Liu L. Y. Journal of construction engineering and management 132, 12, 1234-1241 (2012)

2. Y. M. A. Hashash, J. J. Hook, B. Schmidt, J. I-Chiang Y., Tunnelling and Underground Space Technology 16(4), 247-293 (2001)

3. GOST 23961-80. Subways. Clearance obstructions of work equipment and rolling stock. (Introduced 12.29.1979)

4. SP 120.13330.2012. Subways. The updated edition of SNiP 32-02-2003.( Introduced 01.01.2013)

5. B.E. Slavin. Fundamentals of scientific research of underground structures: Textbook (2004)

6. V.N. Suchenko. Mine surveying support for the construction of tunnels subway: Tutorial (2001)

7. V. A. Garber, Transport construction 5, 12-14 (2012)

8. E.I. Gorokhova, I.V. Aleshina, E.V. Romanovich and others. VIII Intern. Sci. Congress «Interexpo GEO-Sibir-2012» (Novosibirsk, 10 - 20 April, 2012)

9. A.V. Komissarov. Method of research of metric characteristics of scans [Text]: the author's abstract. (Novosibirsk, 2007)

10. E.I. Gorokhova, A.V. Ivanov, Collected materials of scientific. Congress. "GEOSiberia-2009" (Novosibirsk, April 20-24, 2009)

11. H. Park, H. Lee, H. Adeli, I. Lee, Computer-Aided Civil and Infrastructure Engineering 22, 19-30 (2007)

12. R. Van Gosliga, R. Lindenbergh, N. Pfeifer, International Archives of Photogrammetry, Remote Sensing and Spatial Information Sciences 36 (Part 5), 25-27 (2006)

13. Bernd Hiller. Open urban planning forum, session "Safety of construction and operation of objects" (Novosibirsk, 2010)

14. B. He, B. Wang, C. Li, T. Y. Yang, Z. C. Cai, F. Xiao, AMR 718-720, 837-841 (2013)

15. H.H. Bogomolov, Proceedings of the Mining Institute 204, 40-45 (2013)

16. D.A. Afonin, H.H. Bogomolov, M.Ya. Bryn, Geodesy and cartography 1, 7-11 (2014)

17. F. Wang, D.M. Zhang, H.H. Zhu, et al. CMC: Computers, Materials \& Continua 34 (1), 63-81 (2013)

18. K. P. Bezrodny [et al.], Metro and tunnels 1, 30-32 (2012)

19. Boldyrev G.G., Zhivaev A.A. Proceed. Of the 8th Internat. Workshop on Structural Health Monitoring (Fu-Kuo, Stanford University, USA, 2011)

20. V.M. Gorpinchenko, M.I. Egorov, Industrial and civil construction 10, 39-41 (2004)

21. K.A. Aime, Construction materials, equipment, technologies of the century 11, 37-39 (2005)

22. E.V. Potapkin, Industrial and Civil Engineering 12 (2006)

23. V.K. Tarakanovskiy, N.K. Kapustin, A.N. Klimov, Geoecology. Engineering geology. Hydrogeology. Geocryology 6, 551-562 (2010) 